\title{
Tirilogia de Centenarios: Alberto Tauro del Pino, Augusto Tamayo Vargas y Juan Ríos (1914-2014)
}

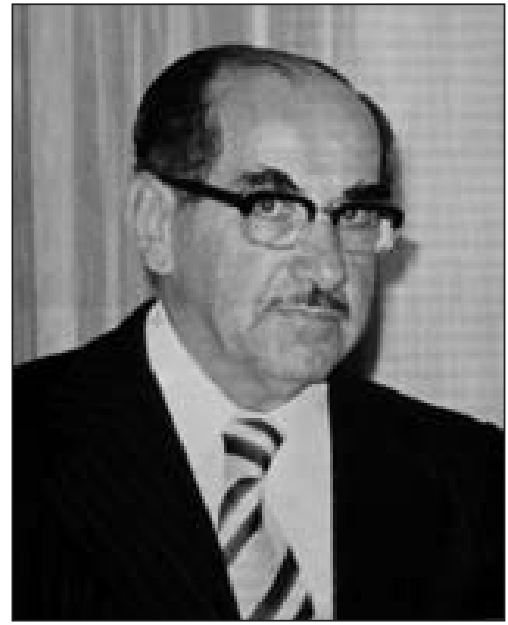

Alberto Tauro del Pino

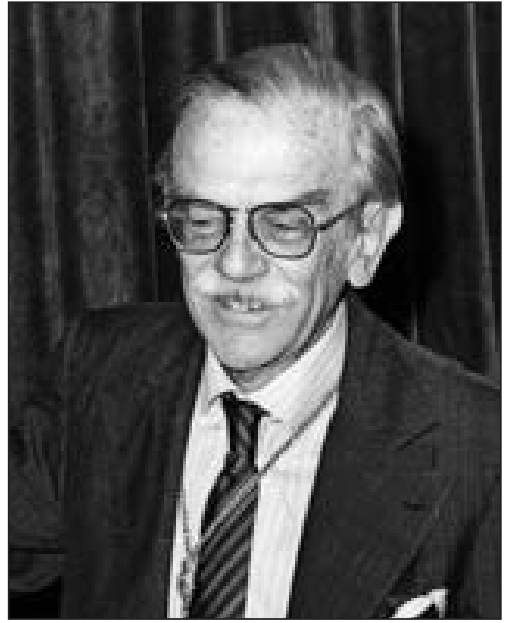

Augusto Tamayo Vargas

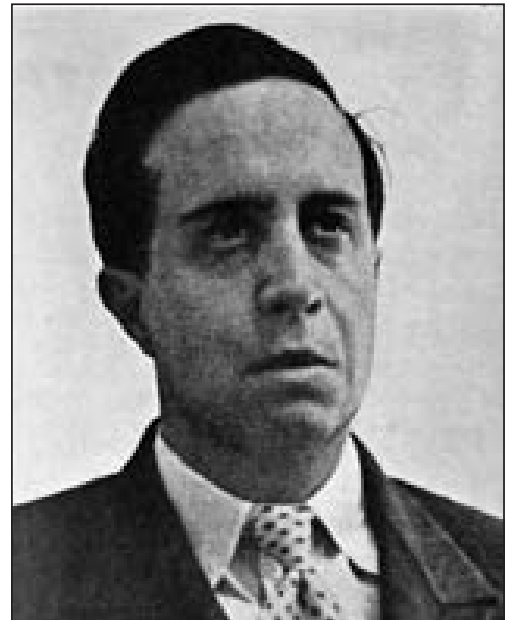

Juan Ríos

\section{Introducción}

1914 fue un año central en la historia contemporánea pues marcó el inicio de la Primera Guerra Mundial que al romper con aquella etapa conocida como la Bell Epoque acentúa otra de espiritu beligerante. En poesía palidecen las góndolas y los cisnes del Modernismo y despunta una nueva forma poética de percibir el mundo, a través de una mirada de lo regional y de un desprendimiento de una retórica artificiosa, que le dan esencialidad a las cosas simples y cotidianas. Ese año de 1914 gobierna el Perú Oscar R. Benavides luego de la revolución militar que pondría término al gobierno de Guillermo Billinghurst (4 de febrero). También es el año del nacimiento de tres escritores destacados de la llamada "Generación del 30-36". Nos referimos a Alberto Tauro del Pino, Augusto Tamayo Vargas y Juan Ríos. Los dos primeros estudiaron en el Colegio La Inmaculada junto con Luis Fabio Xammar, José Alfredo Hernández, Aurelio Miró Quesada, César Miró y Juan Luis Velázquez. Por su parte, Juan Ríos estudió en el Colegio La Recoleta, donde también estarian Enrique Peña Barrenechea, Manuel y Enrique Solari Swayne. Del Colegio Alemán proceden Estuardo Núñez, Martín Adán y Emilio Adolfo Westphalen.

Palabras claves: nacional, universal, Tauro, Tamayo, Ríos, Mariátegui, Eguren, lírica, épica, mito, metalenguaje, tiempo poético.
Una nueva conciencia para ver y sentir el Perú aparece en estos escritores del 30-36 que en gran medida continúan el legado de la "Generación del 19", pero a partir de un nuevo esquema acentuadamente reflexivo y crítico acorde con los graves acontecimientos nacionales y mundiales que les tocó vivir. Desde el punto de vista literario este conjunto está marcado por la muerte de Mariátegui (16 de abril de 1930) y por la de César Vallejo (15 de abril de 1938), e inclusive por la de José María Eguren (20 de abril de 1942). Al incremento de la conciencia nacional de los años 15-30 se ha de sumar un espíritu universal, que es el legado de la vanguardia europea. En estas dos direcciones que vienen del 19 están las oriflamas de Mariátegui y Vallejo: "Peruanicemos el Perú" y "Perú al pie del orbe".

A través de estos derroteros los jóvenes integrantes del 3036 develaron el verdadero rostro del Perú desde diversos frentes creativos y de reflexión social. Despuntaron, así, rutas, tendencias y estilos: la surrealista, simbolista e indigenista; pero también se impulsaron géneros como el narrativo, el de la literatura infantil, el teatral, la crítica literaria (aquí estará, como fundador de la crítica contemporánea, el doctor Estuardo Núñez). 
A continuación nos detendremos en la obra de Alberto Tauro del Pino, Augusto Tamayo Vargas y Juan Ríos con motivo del centenario de sus nacimientos.

\section{Alberto Tauro Del Pino}

(Callao, 17/1/1914-Lima, 18/2/1994)

Una existencia pensada y sentida en función de las raíces más hondas de lo peruano caracterizó a Alberto Tauro del Pino. Ese sustento paradigmático es lo que pretendemos exponer en este homenaje que rendimos a uno de los grandes maestros del Perú en el siglo XX. Su vida intelectual se inicia en el colegio La Inmaculada cuando forma parte de la llamada "Academia Literaria Cervantes" establecida para los estudiantes de los últimos años de secundaria. En este plantel ha de pronunciar, en 1930, el "Discurso de despedida al colegio" en donde ya aparece esa conciencia alerta y ese espíritu a favor del estudio y la reflexión sobre nuestra sociedad que lo habría de signar para siempre. En esa época de adolescente decía que hay que aprender de memoria el diccionario "para no errar en los conceptos". Su precoz madurez ya está presente en los diferentes artículos que escribió en la revista escolar "Prometeo" (1930-1931) que dirigió junto con Augusto Tamayo Vargas. Allí aparecen sus trabajos sobre asuntos como "La convulsión hispanoamericana", "El nacimiento del héroe", "Ideario del pasado y del futuro"; igualmente reseñas críticas sobre la revista española "Bolívar" y sobre "Amauta", "Nueva Revista Peruana", "Siempre", "Universidad", "Horario", "Abecedario" y "Presente".

Comprometidos estaban los adolescentes de entonces con el mito de Prometeo, el personaje inspirador del superhombre nietzscheano. Tauro del Pino escribió el pórtico titulado "Nuestro emblema", donde daba cuenta del significado y del simbolismo -para su generación- de este héroe griego:

Las cadenas fueron rotas, el hombre quedó libre, y después que el tiempo ha transcurrido una generación optimista enarbola el símbolo de Prometeo y se rebela contra la insignificancia, contra el desconocimiento en que la tienen los demás, y aventura sus palabras, sus deseos, las ilusiones que en un momento lírico amamanta, y se lanza, tal vez con un gesto demasiado audaz, hacia lo que todo hombre persigue: la perpetuidad.

Por eso nosotros con este gesto interpretamos nuestro sentir y al romper las cadenas que nos enlazaban a lo desconocido, a la masa sin nombre, damos un paso para alcanzar aquello que alucina y que parece utopía. ("Prometeo" No 1, 1930: 2)

En 1936, un año después de reabrirse la Universidad de San Marcos luego de un receso de tres años por causa de los conflictos sociales y políticos de entonces, Tauro del Pino, Augusto Tamayo Vargas, José María Arguedas, José Alvarado Sánchez y Emilio Champion, editaron la revista "Palabra, en defensa de la cultura" en donde las colaboraciones de Tauro señalan rutas y ofrecen advertencias propias de un pensador prolijo, de ideas progresistas y éticas.

Merece destacarse en "Palabra"su trabajo "Defensa del Indigenismo", que es la base de su posterior tesis universitaria ("El Indigenismo a través de la poesía de Alejandro Peralta") y el verdadero comienzo de ese permanente y sistematizado estudio sobre el Perú. El texto aludido es una respuesta a la colaboración del pintor Teodoro Núnez Ureta, denominada "El indigenismo y el arte", en donde este autor sustenta que "el indigenismo flaquea en su base al inspirarse en el arte de los indios y adoptar una postura falsa y convencional". Tauro le ha de contestar escribiendo con argumentos sólidos "Sobre la verdadera comprensión del indigenismo y su revalorización como peruanismo artístico, popular y progresista”. Y para completar la presencia de Tauro en esta decisiva revista anotemos sus textos "Perú 1945", sobre la próxima caída del nazismo y la unidad del país, y "Libertad", sobre la necesidad del establecimiento de la plena libertad social para recuperar las energías nacionales y el desarrollo de nuestras fuentes de riquezas.

Desde sus intervenciones en las revistas "Prometeo" y "Palabra" es posible rastrear la intensa y coherente producción futura de un polígrafo auténtico que escribió sobre diferentes asuntos y, al hacerlo, lo enlazó en la dirección del amor por el Perú y su cultura. Así hay que calar en sus estudios sobre las revistas de la generación modernista "Contemporáneos y Cultura"; también su trabajo sobre "El espejo de mi tierra" referido a la obra periodística de Felipe Pardo y Aliaga; la revista "Fénix" de la Biblioteca Nacional, de la cual fue director, así como los nueve volúmenes del Anuario Bibliográfico Peruano que registra lo producido en el país desde 1943 hasta 1954; también su Bibliografía Peruana de la Historia, Bibliografía Peruana de Legislación y Estudios Jurídicos (desde 1935 hasta 1957), su Guia de Estudios Históricos (1955), su Bibliografía Peruana de la Literatura (entre 1951 y 1958), Hacia un catálogo de seudónimos peruanos -editado en 1965 y cuya segunda edición dejó lista antes de fallecer-, su Bibliografía del 
Inca Garcilaso de la Vega (1966); y, en otra dirección su estudio sobre Manuel de Mendiburu, el autor del Diccionario Histórico biográfico del Perú; y, finalmente, ese portento que es su Diccionario Enciclopédico del Perú, en tres volúmenes y un apéndice. En la introducción de esta inigualable obra, Tauro reafirmará esa pasión tan suya por definir el rostro del Perú y su cultura como base para incitar la toma de conciencia de una personalidad nacional:

Ha sido diseñado -dirá- como un cuadro general de los conocimientos sobre la realidad y la trayectoria del Perú, y sobre la obra creadora de los peruanos: bien, para superar la dispersión y la inaccesibilidad de observaciones e investigaciones, eventualmente olvidadas en oscuros rincones de bibliotecas y archivos; o bien, para ofrecer una visión actual de las informaciones que han delineado la figura histórica del país y la acción cumplida por sus hombres.

Este recordado maestro, al recibir las insignias de Profesor Emérito de la Universidad Nacional Mayor de San Marcos, el 25 de agosto de 1986, expuso en un magistral discurso sus puntos de vista sobre lo que llamó metafóricamente "Diorama de la crisis universitaria". Como se sabe, diorama es una composición de gran tamaño en una tela sin bordes visibles, sobre la que se ejercen juegos de iluminación ante espectadores sumidos en la oscuridad. Pues bien, Alberto Tauro del Pino representó allí a San Marcos y a su larga historia. La tela sin bordes visibles pudo ser su propio discurso ofrecido para iluminar a tantos -de la misma universidad inclusive- sumidos en la ignorancia o el error. Al terminar sostuvo que "la crisis universitaria es un reflejo de la política seguida por el Estado en lo atañedero a la atención de los requerimientos institucionales. Es una política basada en la incongruente interpretación de la autonomía -dijo-, que en lo interno deja a las autoridades la difícil tarea de administrar la escasez de las previsiones presupuestarias y de atender a los problemas consiguientes...".

Estuardo Núñez, el hermano mayor de esta generación escribió en la revista "Fénix" el artículo "Alberto Tauro en la Cultura Peruana", donde dice:

Los que militábamos en la reforma universitaria de 1930, cuando aún estaba el debate vigoroso, abarcador e integral del hecho social promovido por José Carlos Mariátegui, pudimos anotar el

1 Tauro del Pino, Alberto, "Diorama de la crisis universitaria". Suplemento de la Gaceta Sanmarquina № 2, Lima, agosto de 1986. advenimiento del grupo de la revista "Palabra" que conformaban Augusto Tamayo Vargas, José Alvarado Sánchez, José María Arguedas y Alberto Tauro. Significaron los nombrados, y muchos más, la renovación de la inquietud dirigida a lograr un Perú mejor y además auténtico y constructivo. Alberto Tauro fue una de las voces más esclarecidas de esa generación y un intelectual verdadero y eficaz. Tauro no había alcanzado a conocer a Mariátegui pero en los años posteriores a 1930 bebía de sus libros la inquietud en los Siete ensayos (1928) y en las páginas cristalinas y sagaces de La escena contemporánea (1925) y más tarde en los cabales ensayos de El alma matinal (1950). ${ }^{2}$

\section{Mariateguista esencial en doctrina y conducta}

Arduo esfuerzo significa sistematizar la monumental obra de Alberto Tauro. Ese es un trabajo de investigación que deberá realizarse necesariamente. Por el momento, y para los efectos de la intención de este homenaje, queremos referirnos a esa predilección de Tauro por los estudios sobre José Carlos Mariátegui. Por rara y estremecedora coincidencia, su vinculación con el gran pensador peruano se ha de manifestar hasta en el momento mismo de su muerte puesto que él fallece precisamente el año en que se conmemoró el centenario del nacimiento del Amauta (1994), cuando ocupaba el cargo de Presidente de la Comisión respectiva. Como ya hemos dicho, la relación íntima con Mariátegui aparece desde la época de la revista juvenil "Prometeo"cuyo local quedaba en el jirón de la Unión. En una entrevista que le hiciéramos algunos años antes de su desaparición nos manifestó:

Desde el Jirón de la Unión pude ver el entierro de José Carlos Mariátegui en abril del año 30. Fue un espectáculo impresionante, aunque en ese entonces nosotros no teníamos ningún conocimiento de su gran valía.

Sobre "Amauta", la revista de Mariátegui, Tauro ha dejado estudios magistrales dentro de los cuales destacamos: Amauta y su influencia (1960), con un prólogo que es un derrotero cabal; "Noticia del Amauta", estudio erudito aparecido en la edición facsimilar; los prólogos a La Novela y la vida y a El artista y la época, en donde destaca la concertada unidad, sin dogmas, del arte con la historia, de la realidad con la fantasía.

2 En "Fénix" N³6-37, revista de la Biblioteca Nacional del Perú, 1994. 
La impronta mariateguista signa, pues, de una u otra forma, todos los escritos de Tauro del Pino. En sus artículos de "Palabra", en sus estudios bibliográficos e históricos (dentro de los cuales sobresale su Historia del Perú Republicano), en sus investigaciones sobre Amarilis Indiana y sobre Esquividad y gloria de la Academia Antártica, en sus trabajos sobre el indigenismo (especialmente de Alejandro Peralta y Clorinda Matto de Turner), en sus estudios sobre personajes peruanos (Amézaga, Castilla, Luis Benjamín Cisneros, Chocano, Gamarra, Laso, Luna Pizarro, Martínez Luján, Palma, Pardo y Aliaga, Segura, González Vigil, etc.), en sus ensayos sobre cultura bibliotecaria, Tauro del Pino nos ha dejado -continuando la ruta trazada por Mariátegui- su propia doctrina en donde aparece, con rigurosa honestidad intelectual y amor por lo nuestro, la realidad y la trayectoria del Perú como base para vislumbrar su destino sustentado en la libertad, la justicia, la seguridad, la solidaridad, la generosidad, el desprendimiento. En su brillante discurso de incorporación a la Academia Peruana de la Lengua, el 28 de agosto de 1980, titulado "Concepto del Perú”, Tauro del Pino dejó sentada su envergadura moral y ética al trazar una especie de correlato entre la idea de país y la conducta individual y social que subyace en ella:

El concepto del Perú debe emerger de la identificación total con la traducción y el destino del país y de sus gentes. Debe nutrirse de las observaciones y las expectativas, las ideas y los designios que día a día coadyuvan a reconocer y mejorar la morada común. Debe consultar los avisos de una vigilante preocupación ante las influencias que puedan obstruir o deformar el desenvolvimiento colectivo. Y conjugar la asunción del legado histórico, la experiencia vital, la decantación del conocimiento y las demandas generales, así como las energías del afecto y la pugnacidad. Su formación coincide con el desarrollo de la conciencia nacional; y su correcta formulación solo puede sustentarse en una visión desde adentro.

Más adelante, en esta especie de retrato personal, ha de señalar, con claridad conceptual y perspicacia, que el concepto del Perú no se puede limitar a una noción geográfica ni al reconocimiento internacional imbricado en el juego de los tratados.
La voz de Tauro y su mensaje nos siguen acompañando con dramática pertinencia:

Es mucho más, porque abarca las circunstancias objetivas del ambiente y del hombre, los valores subjetivos de la tradición y la cultura, la relación entre las gentes y sus gobernantes, la correspondencia entre la ley y la existencia cotidiana (...) debemos volver constantemente a la búsqueda de las antiguas raíces de nuestro pueblo, y a sondear una y otra vez en las fuentes de nuestra cultura, cuando el destino del país requiera de una orientación luminosa, la voluntad constructiva que a todos beneficie, y aun el gesto generoso determinado por el afecto franco. Como en los días legendarios de la fundación del Cuzco, debemos considerar a nuestra tierra como el centro del mundo, en cuanto su realidad y su destino constituyen el punto de apoyo desde el cual emergemos a la vida, y el lugar hacia el cual deseamos que converjan los mayores avances del saber y las más activas formas de la felicidad social. Lejos, ya, de las discriminaciones impuestas por la violencia, e injustamente mantenidas por el egoísmo y la soberbia; lejos de esos privilegios contrarios a la dignidad ajena, y merced a los cuales prevalecieron la ineptitud y la indolencia; lejos de los exclusivismos que a veces buscan amparo en los pronunciamientos de multitudes turbulentas y tornadizas. Fatigosamente construido por indígenas y españoles, por criollos, mestizos y negros, y por hombres de buena fe que desde latitudes diferentes han acudido para establecer en su suelo una morada cálida” (...) "El Perú es un país de síntesis, que en su pasado halla las más fecundadas lecciones y puede mirar confiadamente el futuro".

La cultura vital, sin diletantismo, como postulaba Ortega y Gasset, fue siempre la oriflama de Alberto Tauro del Pino, bibliófilo y maestro fervoroso que pasó toda su vida pensando sobre las raíces orientadoras del desarrollo espiritual del Perú. Ese fue su temperamento. Así lo conocimos, con toda su pasión bibliográfica y crítica de los escritos sobre historia y sus fuentes, y de los autores que han tratado de estas materias. Así lo tratamos e intimamos desde que fuera nuestro profesor en las aulas sanmarquinas y, luego, colega y guía en múltiples labores literarias y docentes. Así resplandeció su sabiduría en el viaje que con él y con César Miró 
realizamos a Costa Rica, en agosto del año 93, para hablar sobre distintos aspectos de la cultura peruana. Al escucharlo entonces sabíamos que ponía en evidencia aquella voluntad suya que luego dejaría escrita en el conocido artículo denominado "Elogio del libro":

Muchas veces he deseado hallarme ante un auditorio reducido e inteligente, sin estar previamente comprometido a desenvolver algún tema determinado por la expresión de un interés circunstancial. Y, hechos ya el silencio que a todos impusiera la expectativa, he imaginado que sería posible crear una nueva y fecundada relación con los oyentes, mediante el ofrecimiento de sujetar mi disertación a la respuesta que en común pudiera formularse para dilucidar una cuestión cultural. Equivaldría a revivir el sereno y sutil diálogo que animó Platón, entre los aromas y los halagüeños susurros del jardín de Akademus; o la activa participación que cupo a los discípulos de Aristóteles en el metódico esclarecimiento de los problemas filosóficos. Sería aproximarse a la emulación de un ideal clásico en el cual se impondría el respeto a la opinión ajena y el libre ejercicio de la razón. Pero íntimamente no dejo de considerar cuántos peligros se derivarían del nerviosismo, las tendencias dogmáticas y las explosiones tumultuarias: pues tan frecuente son en nuestros días, que suelen contradecir la cortesía y el discernimiento.

Refinada calidad humana como sustento de una ejemplar postura intelectual; intelecto encarnado en su propia vida, y viceversa; y profundo compromiso consigo mismo y con el Perú: así recordamos al gran maestro y amigo que con emoción le sacó brillo a las ideas en su calidad de indiscutible cumbre de la historiografía peruana.

\section{Augusto Tamayo Vargas \\ (Lima, 6/09/1914-6/05/1992)}

Tamayo Vargas es el iniciador de la tradición abrileña con un artículo que ganó el Premio Cabotín de 1957, titulado "Abril en la Literatura del Perú", donde pone luces señalando que en este mes nacieron y fallecieron grandes escritores peruanos como Garcilaso, Vallejo, Mariátegui, Valdelomar, Eguren, Salaverry, etc. Autor, además, de la monumental Literatura Peruana (3 tomos) que desde 1953 tuvo varias ediciones hasta llegar a ser la mejor historia de nuestra literatura escrita hasta el momento, fue, además, uno de los altos poetas representativos de la "Generación del 36", como lo vamos a corroborar en estas líneas.

\section{Emprendimiento del poeta en el lugar más lírico del} canto épico

Después de los primeros tanteos recogidos en Experimentos vanguardistas (1930-1933), su libro Ingreso Lírico a la Geografía (1934-1939) estableció las coordenadas de sus cualidades expresivas: la idea de proceso, de avance constante de la historia en donde aparecen los más remotos contactos del hombre, o viajero de la tierra,dejando su huella y su impronta para cambiarla permanentemente, reviviendo los mitos más antiguos del "ser humano como hacedor", como constructor que hace crecer la fuerza y la luz a costa del arado o el buril hundido en la madre hembra-tierra. El poema inicial de este libro es ejemplar:

\section{Hay en el arado}

la insólita apariencia de una vida remota, despintada en la tierra con colores de rama, con esencia de sombra en los brazos abiertos.

Rondando en la semilla

el campesino arrastra su imagen

desde el trasfondo negro de pasado continuo

hasta el mundo que insurge en su espalda.

El hacerse superior a los obstáculos y a las adversidades es la lucha que plantea el poeta; lo que significa el reconocimiento de dos variables que controlan la existencia y pugnan por entronizarse: el sentimiento de derrota que es siempre de ruptura, desorden y estrago, y el sentimiento de afirmación que impulsa hacia la construcción y hacia los logros más edificantes. La poética de Tamayo Vargas fue marcando estos dos pasos a través de toda su obra. Algunos títulos expresan esa dualidad, tal el caso de Poemas de muerte y esperanza (1940-1945). Aquí el autor, contrastando su acento con los Cantos de vida y esperanza, de Darío, construye un poema en seis partes que plantea -a partir de la conmoción producida por la destrucción nazi- la doble violencia de la muerte y de la vida. En ellas el poeta nos dice que la vida ha sido hecha para ser vivida, no para matarla, y que de los escombros ha de surgir la nueva redención prometeica; de las sombras se alzará el fuego liberado, de los huesos emergerá la carne, y brotará de la semilla-noche la espiga-verdor. El mensaje que aparece en los versos finales de cada uno de los poemas merece ser destacado:

"Los hombres tenían por hacerse un mundo y han de revivirlo sobre frescos túmulos". 
"Con la metralla y la granada hechas, sobre los bíceps del hombre que pelea; espigarás para la vida nueva”

"Los anhelos colmados aquí están esqueletos para un mundo de sombras que forjaron los tanques".

"Para tu imagen nueva se olvidarán los siglos".

"Un alba muy blanca detrás del velero.

Ha partido el viejo con la niña al hombro

y está crepitando de nuevo la tierra”.

Colocado en el lugar más lírico del canto épico, Tamayo expone su resonancia personal, efectiva, de los acontecimientos extremos que se narran. Algo de Píndaro viene con estos versos, por la inventiva audaz, por la energía de la expresión, por la abundancia y riqueza de las imágenes, por el calor que impulsa el relato interiorizado.

\section{El mito como metalenguaje del origen del hombre y del poeta}

El "Poema de Vichama", que forma parte del libro Camino de Poesía (1946-1949), reproduce acertadamente no solo el mito del origen del hombre en la costa del Perú, del desarrollo de las especies vegetales y animales y del proceso social del cultivo en la zona desértica, sino que expresa también el "mito del poeta", es decir, el mito "como forma, como estructura de existencia” en la definición de Gusdorf. No es el "Poema de Vichama" la única muestra clara del mito del autor, pero es una de las más significativas por su poder de condensación. Esa "estructura de existencia" es la que crea "su" verdad y está ligada al primer conocimiento de sí mismo y del mundo que lo rodea. Así pues, para el mito de Tamayo, la "vidamuerte-renacimiento" constituye una tríada que está ubicada dentro de nuestra propia tierra, sin ningún tipo de especulación metafísica:

El hombre deidificando la materia y orando ante las lenguas de tierra; y llevándole incienso y licor de maíz.

Y crecieron los años sobre los hombres.

Y se formaron como huaycos los cantares.

Para cuando la tierra se cubra de brotes; para el amanecer, para el camino, para los amores y para el hijo; para la niebla de la angustia; y para el morir.
Otro poemario importante:Estación y éxtasis (19501957) recoge un testimonio emotivo de su permanencia en Río de Janeiro. En este libro se conjugan las dos direcciones de su poesía: la del compromiso con la naturaleza y con el hombre que la habita; y la de la apreciación plástica de la propia palabra poética, recreada con nuevos aires de modernidad: "Tupi, tupi, tupiyé,/ para mulangús de incendio./ Para las medusas prietas,/ Cayú, cayú, cayuá”.

Pero no se trata solo de la unión de las dos vertientes. Se trata también de llegar al punto exacto en donde naturaleza y belleza condicionan el arrobamiento como máxima "acción de estar", en donde se hace más ostensible la presencia del cuerpo que queda y del espíritu que vuela buscando su "ración de belleza". Manuel Bandeira, el vate del Brasil, dijo en su momento:

Cuando estos poemas salgan a la publicidad verán los brasileños cómo esa ración de belleza fue asimilada por nuestro sensible visitante, y cómo ella fue transmutada en otra categoría de belleza tan conmovedora como la natural y menos perecedera.

En 1966 Tamayo Vargas publicó, en Argentina, Nuevamente poesía (1958-1965), y en 1970, en México, Amor por América la pobre (1968). La importancia del primero radica en su condición de antología realizada por el propio autor en la que aparecen poemas ya publicados junto con otros inéditos a través de los cuales es posible rastrear los significantes de su estilo poético e interpretar la etiología de los mitos personales. Este libro también es significativo porque, en oposición a la tendencia alborozada, introduce la tierna y melancólica línea del "regreso", especialmente en las secciones denominadas "Poemas de la soledad y del atardecer" y "Poemas del aire". Estos ejemplos pueden ser suficientes:

¿No lo saben, amigos? conforme pasa el tiempo

la luz es más oscura;

hay un lamer de voces que vienen desde el fondo; muchas rosas se pudren en los sucios rincones de los cuartos; el pan pasa muy lentamente por la garganta; y todo adquiere un aire de distancia.

(Simplemente") 
Perdida el ala

camino del regreso,

así me encuentro,

raíz del alma.

\section{("Regreso")}

Pero la esperanza, como deseo y confianza que sublima la realidad, es una posta que debe ser recibida cuando las fuerzas flaquean. Y por eso ahí está "Esperanza en los días que vienen”, que alcanzara gran popularidad en Argentina:

Yo tengo el corazón puesto sobre el futuro.

Puesto en los hijos que de mis hijos vengan.

Puesto en el corazón de los que vengan luego.

Puesto en los miles que han de vivir mañana.

\section{Exaltación cósmica de pasado, presente y futuro}

Dos largos poemas: "Bolívar es la lucha que no acaba"

y "Cantata augural a Simón Bolívar" están en este recorrido que asimila las huellas pasadas para integrarlas con el futuro del continente. El gran aporte se da, sin embargo, en Canto Coral de Indias, Capitanes y Astronautas bajo los cielos de América (1977). En este texto, la exaltación cósmica, que ya venía germinando en anteriores poemas, alcanza un tono mágico y heroico simultáneamente. Por intermedio de un lenguaje destellante y de metáforas en permanente expansión, se sustenta una composición que avanza por los caminos del canto épico, con sus divisiones marcadas por personajes que "tañen cascabeles"; por hombres -semidioses o héroes parecen- que tocan a "tambor batiente"; por sonoras voces que "acompañan los motores" y le dan el acompañamiento coral a los que compiten en el gran estadio del universo por la paz y la fraternidad, desde Píndaro a Gagarin, pasando por las profecías de César Vallejo: "Y la espiga será por fin espiga". Este texto de Tamayo, que tiene toda la fuerza dramática para ser representado, recorre y reconstruye, en sus progresivas tensiones (nuevamente la estampación del "desplazamiento"), el pasado, el presente y el futuro de América alzada ante el mundo. La pirámide de este canto americano que apunta hacia el cosmos contiene uno de los lenguajes más ricos y bellos de la literatura de nuestro tiempo:

Los ovnis han incendiado el orbe.

Corren atletas en el espacio olímpico y detrás de la atmósfera los satélites

se embriagan de Luna y Marte

y rompen los moleños de Mercurio

y las carnes de Venus

para traer las piedras a este mundo

y otra vez hacer mover a los molinos.

Hay una luz intensa

y un solo pan para todos los habitantes de la tierra.

¡Ea! ¡aleluya! ¡Hurra!

Con Arco en el tiempo (1966-1971) encontramos otro momento en el lenguaje del poeta. Por un lado se extienden los temas hacia las resonancias interiores, insistiendo especialmente en la soledad, la familia, la observación de las cosas, etc. Por otro lado, el trabajo formal depura, ciñe e intensifica más al verso. Por primera vez aparece, de manera notoria, el poema corto, como este que siendo todo una poética abre el libro:
Hay un camino de árboles, un mar al fondo, pero tan solo miro, el pequeño guijarro hecho de siglos que tantas manos apretaron.

\section{Proceso de exaltación, arrobamiento} de la soledad y hallazgo de la vida

Desde Ingreso a la Geografía (1939) hasta Arco en el tiempo (1971) es posible observar en la obra de Augusto Tamayo Vargas un movimiento que partiendo de la administración y exaltación a la vida se introduce en la confluencia donde acuden, dramáticamente, el arrobamiento frente a la naturaleza y el sentimiento de soledad y de tristeza. Este último acento, sin embargo, no hace perder su permanente norte esperanzado. En Hallazgo de la vida (19711979) el proceso que hemos diseñado se invierte. En efecto, si en el primer caso nos encontramos directa y casi "físicamente" con una poesía en donde la vida es un hallazgo deslumbrante que llega a nuestros ojos sin proponernos, en el segundo caso -el último libro- la vida es el producto de una búsqueda y de un descubrimiento que surge de nosotros mismos a partir del esfuerzo algunas veces doloroso y otras exultante.

Los títulos musicales de los textos de Hallazgo de la vida, libro maduro, de lenguaje destilado e intenso, nos conducen hacia la dimensión del gozo como vibración interior del ánimo y como diapasón que regula la voz 
del poeta, sintonizada con el tiempo de su propio ser. La "visualización" de este desarrollo emotivo se da, a partir de "Adagio" (movimiento lento), como aceptación de una realidad cruel que rodea nuestra existencia:

\section{Admitámoslo.}

Nos hallamos exhaustos, adormilados

frente a horrores de sombras detenidas, de paredes salpicadas de sangre

de romas cuchillas abriendo sus bicéfalas mandíbulas,

de siniestros azotes en turbios callejones

de no tener el vaso de agua

cuando la sed nos teje su verde telaraña.

Posteriormente, en "Andante", el movimiento se acelera:

\author{
El océano, en tanto, viene andando \\ camina, \\ lentamente ondulando. \\ ¿No lo sientes acaso cómo avanza \\ todavía \\ hasta ungirnos las manos?
}

Este tiempo interiorizado es luego, en "Scherzo", un movimiento incontenible, una flecha que se proyecta desde el pasado hacia el futuro en la búsqueda de la belleza alucinante, de aquella luz que permanece en el horizonte, más allá del olvido:

\section{De Capricornio al Acuario,}

desde candente hierro, sangre cierta, núbil cuerpo de ingrávida Amaltea a atmósfera de agua que nos cubre, y que inunda de luz hasta las vísceras, el año pasa hacia el final del año.

A cada rato repican los cohetazos.

\section{Condensación del mundo representado en un fabulario de amor}

En 1983 Augusto Tamayo Vargas sorprendió a la crítica con su libro De las gaviotas y el tiempo (Ed. Corona del Sur. Málaga, España), no tanto por el reencuentro de la esperanza después de una etapa de postración en lo personal -reencuentro que, como lo hemos reiterado, se constituye en un ingrediente básico de su poética- sino por la renovación de la propia estructura, de los mecanismos de la misma expresión, especialmente en el campo de las asociaciones sistemáticas, o imágenes, mediante las cuales consigue que el mundo representado se condense sin perder -más bien ganando- en fluidez y transparencia.
Comprometido con el fondo mismo del vivir y sentir, la palabra rescata esa realidad honda, aunque al ser expresada ya es otra realidad: la poética. El trasiego permite captar toda la intensidad del amor, o eco mismo de la poesía; igualmente, consigue entender las sutiles relaciones y los cruces que existen, de una parte, entre la realidad y el sueño de las vivencias; y de otra parte, entre la realidad y el sueño de la palabra. Estos binomios se proyectan, al final, en la sola imagen -simple y compleja- de una poesía estremecida:

Me lleno de pronto

de una alegría simple

que apenas si es reflejo

de lo que los ojos están mirando por dentro

de lo que los oídos escuchan con rumor interno

de lo que los labios remembran

como gotear del líquido que los humedece

con solo el pensamiento

que recorre el cuerpo

y electriza los nervios

para que vuelva después sobrecogido

al punto del éxtasis.

("Epifanía del amor y del agua”)

Tamayo nos fue descubriendo en todo su recorrido existencial-de manos dadas con el tiempo del hombre y del universo, con su naturaleza y con su palabra- la odisea de una vida, o de una obra, que se mantuvo "frente a la mar que es el vivir". Esta imagen del mar será el gran símbolo totalizador de su poesía. Su intuición o visión estética le hizo sentir, en su propia naturaleza física y espiritual, a la eternidad constantemente removida, porque para él no fue la agonía de la ola que muere en la arena con angustia sino la agonía de la ola que ansía volver siempre al mar, con vehemencia. Y en todo esto estará también la vida que se halla a sí misma, que se encuentra consigo de repente; o la vida que inventa su propio cauce para permanecer o estar siempre en plan de futuro, por encima de cualquier abrojo, mostrando su alarde de eternidad a través del canto.

\section{Juan Ríos}

(Lima, 28/9/1914-15/11/1991)

Juan Ríos estudió en los colegios Belén y Recoleta. Luego de cursar un año en la Universidad Católica del Perú viajó a España en 1934 e ingresó a la Universidad de Madrid. En 1936, cuando se inició la Guerra Civil Española, se enroló en las milicias republicanas, como muchos escritores que empuñaron el fusil en favor de la causa de la República, y peleó en la sierra de Guadarrama hasta que por agotamiento físico 
fue enviado a un hospital de Madrid. En la orden de evacuación constaba que pese a la prescripción médica solo aceptó dejar el frente cuando su regimiento logró rechazar el ataque enemigo. En ese año del 36, en esa sierra mancillada por los cañones, moriría el poeta puneño Carlos Oquendo de Amat, el célebre autor de 5 metros de poemas. Ríos se trasladó a Francia donde se matriculó en La Sorbona. Al enterarse de que padecía una dolencia cardíaca decidió dedicarse a la literatura y empezó a escribir poemas. De vuelta al país tuvo que optar entre la prisión o el destierro. Su militancia marxista era incompatible con el gobierno de Benavides. Estuvo nuevamente en el frente de Madrid, pero esta vez en calidad de Corresponsal. Posteriormente vivió en París hasta 1940, regresando al Perú al cambiar el gobierno. Desde esa fecha se dedicó con decisión a su obra literaria, logrando siete premios nacionales: cinco de teatro y dos de poesía. En 1975 ingresó a la Academia Peruana de la Lengua.

\section{El Teatro dentro de la Generación 30-36: Juan Ríos}

La propuesta teatral contemporánea del Perú se consolida en esta generación del 30-36, especialmente en las obras de Juan Ríos quien tardíamente publica Don Quijote (1946), La selva-Medea (1950), Ayar Manko (1952), El mar (1954) y Los desesperados (1960), todas ellas merecedoras de premios nacionales. Además publicó El reino sobre las tumbas, en 1957.

Especie de poesía dramática o de teatro épico, en Ríos se hace evidente su amor por los mitos universales. En general, ellos aparecen con mucha fuerza en esta generación por la capacidad que tienen para revelar raíces o esencias, tanto nacionales como universales. En poesía, dos ejemplos pueden ser representativos de esta referencia mítica: La mano desasida (Machu Picchu como esfinge de la infinitud), de Martín Adán, y El mito de Vichama (percepción profunda de la vida y la existencia), de Tamayo Vargas. Lo dramático en las obras de Ríos está en las acciones que se extienden al futuro como revelación de los más altos y nobles impulsos del hombre.

El teatro de Juan Ríos es sublime y cultista al mismo tiempo; se caracteriza -como él mismo lo señalara al referirse a su obra Don Quijote- por su huella trágica en el sentido de querer mostrar la nobleza de la condición humana, de creer que la "fatalidad heroicamente aceptada o enfrentada se convierte en destino" y de intentar mostrar un teatro total mediante la síntesis de distintas artes. Roland Forgues, el gran peruanista, ha dicho al respecto en su texto sobre Teatro Peruano:
Lo que merece destacarse en el teatro de Juan Ríos es que, por lo común, los hombres se mueven en un ambiente de grandes conflictos y de devastadoras pasiones cuya presencia se ve magnificada por el coro, y a veces la música y la danza que se combinan en una especie de ballet, igual que en la tragedia griega, en este mundo de incontenibles ardores. Los personajes crecen en el dolor o en la muerte. ${ }^{3}$

Al final de Don Quijote el héroe exclama antes de morir: "De mi cadáver puede crecer un mundo! jla muerte es bella! ¡la muerte es pura! jla muerte es vida!" y, mientras suenan las campanas triunfalmente, los mendigos, invisibles para otros personajes, rodean el lecho de Don Quijote y repiten en coro: "ila muerte es bella! ¡la muerte es pura! ¡la muerte es vida!”; o a la inversa, se envilecen por el crimen en su ansia de poder y dominación, como sucede en El reino sobre las tumbas, donde Marco (uno de los personajes) tras haber matado a su hermano se autoproclama nuevo sacerdote-rey del templo de Nemi: "Y Yo soy ahora el sacerdote, el vencedor, el invencible! ;Mía es la corona! 'Mios son los templos y la floresta! ;Mios son el lago transparente y la medida filuda de la muerte!". Y mientras corre frenéticamente de un extremo a otro incendiando ambas piras, suelta este último grito: " $Y o$ fui, yo soy, yo seré aún, mientras no muera".

"Los Desesperados", tragedia realista, trata sobre la frustración de la generación a la que pertenece el autor, frustración que tiene que ver con el problema del ejército y el partido aprista. Uno de los personajes de la pieza -Vicente-, dice al respecto:

La vida es cruel. No todos pueden ser puros. Y nadie que ame profundamente a la humanidad debe enorgullecerse de serlo. Es necesario aceptar a los hombres como son, ayudarlos a llevar todas sus cargas, aun la del delito. No es suficiente compartir el sufrimiento y la miseria. Es necesario compartir la humillación, el crimen, el remordimiento. Hay que ser también hermanos en el fuego, hermanos en la vergüenza. No basta con sentir pena de los demás. Hay que compadecerse de uno mismo. Solo porque podemos apiadarnos de nuestra propia condición somos superiores a los animales. ¡Cuando todos hayamos conocido alguna vez esa infinita, maravillosa misericordia, el mundo será puro! ¡ $\mathrm{La}$ hora de la redención y el perdón habrá llegado!

3 Colección Palabra Viva.Hablan los dramaturgos, Lima, Editorial San Marcos, 2011: 18. 
Hay un enlace indiscutible entre el teatro y la poesía de Juan Ríos: uno explica al otro, sobre todo a nivel de símbolos.

\section{El tiempo poético como estremecimiento cíclico interno y externo}

El prólogo de Primera Antología Poética le pertenece a Xavier Abril quien realiza allí una exégesis minuciosa de su obra. Su gran aprecio por ella le haría decir: "Ríos pertenece, conviene subrayarlo, al grupo más notable de la poesía peruana. Lo veo yo al lado de Eguren, de Vallejo y de Oquendo de Amat. Cuando Ríos exclama sorprendido “Estoy despierto? ¿O sueño todavía?, es porque sabe que la poesía es un ejercicio constante que oscila entre el despertar y el soñar". En esta primera muestra de su poesía se reúnen textos que a decir del autor en las palabras liminares: "Corresponden en algunos casos a muy distintas fechas, y no fueron escritos siguiendo un plan rigurosamente establecido, sino en armonía con la involuntaria e incesante espiral de los estados de ánimo".

Esta confesión no es solo importante en cuanto significa un buen derrotero para evitar caer en cronologías y paralelismos simplistas sino porque explica con precisión la poética del autor, marcada por esa adhesión al tiempo como fenómeno cíclico, tanto interno como externo, que impregna y compromete todo el discurso poético. Leamos el siguiente fragmento:

Gira inmóvil en torno de su ser

y porque no tiene

principio ni fin

ayer será

mañana fue

ahora es siempre ("El tiempo")

Efectivamente, el tiempo -a la vez beatífico y agónico, pero siempre heroico por esa mezcla de historia y de mito- implica a los tres grupos de volúmenes que estructuran el libro: "Las Tinieblas", "Tierra Firme" y "Universo Transfigurado". El tiempo tiene el valor de potencia cósmica, de orientador existencial de las tres direcciones dentro de la que actúa la poesía de Ríos. La múltiple irradiación psíquica, en términos de temporalidad, está en su obra dirigida hacia la epopeya, el drama y la lírica.

Aún más elevadas son las torres de acero y de cristal que levantamos en la ciudad del tiempo. Pues ahora todos nosotros somos habitantes de la ciudad del tiempo, donde todo le pertenece al tiempo, donde el mismo espacio no es espacio sino tiempo.

De modo que por alto que subamos -pese a ser invisibles las murallas de la ciudad del tiempo- solamente el tiempo lograremos contemplar quienes en la ciudad del tiempo estamos.

("El tiempo")

Siguiendo al poeta alemán Jean Paul, podríamos decir que lo que en la poesía de Juan Ríos existe de epopeya hay que rastrearla -sin que esto signifique limitación ni norma sino descripción de rasgos comunes- en los acontecimientos que vienen desde el pasado, o desde la historia, y son depositados en un conjunto de impresiones y sensaciones subjetivas. Por otro lado, lo dramático en sus textos está en las acciones que se extienden al futuro como revelación de los más altos y nobles impulsos del hombre. Finalmente, lo lírico acapara esa sensación incluida en el presente desde el cual Ríos se compromete con la existencia como una totalidad que incluye a los dos tiempos anteriores. De esta manera, "Las tinieblas", "La tierra firme" y "El universo transfigurado", grupos de volúmenes que, como hemos dicho, estructuran su Primera Antología Poética, estarían apuntando al pasado, al presente y al futuro respectivamente, pero no como casilleros uniformes sino como tendencias en cada una de las cuales, y dialécticamente, funciona también el mismo tríptico temporal.

Pasa la infancia, huye la gozosa

edad de la inocencia, la armonía...

Se desgarra la vida presurosa

y anochece de pronto a mediodía...

¡Oh codicia del alma avariciosa, agonía sin fin, solo agonía, agonía en el tiempo lastimada, agonía en lo eterno consolada!

¡Aquellos que en el centro de la muerte se sientan, al morir, acompañados, aquellos cuyo amor será más fuerte que el gusano en sus pechos devorados, aquellos que animando el polvo inerte volverán en su esencia transformados, hermanos han de ser de los vivientes, silenciosos, invictos, trascendentes! ("Segundo Canto")

Pero más allá de esa solidez estructural, y cubriendo todos los espacios de la materia y la forma poéticas, la 
poesía de Ríos nos llega como un solo estremecimiento que fluctúa entre lo delicado y lo abrupto, entre la soledad y el vacío. Hay mucho de nostalgia del mundo que se pierde, envenenado y agonizante a pesar de su plena vida; hay algo así como un iluminado y tierno infierno terrenal, con toda su alucinante agonía:

Estrella que me matas con la llama que alumbra, ardiente sello, aurora inolvidable, estás en mi recuerdo.

Estás en mi recuerdo cual el arma en la herida, cual el ruido del mundo en el ansia del condenado. (...)

¡Porque el amor es más fuerte que la luz en los ojos del ciego,

porque el amor es más duro que la noche, que la muerte misma,

que el desamparado ensueño cuando duele la vida! ("Canción de siempre”)

\section{La hermosa verdad del vivir o el amor que nos vence}

La atmósfera poética de los textos de Ríos está marcada por una gran limpieza y un gran destello verbal. Hay en ellos un ímpetu "magnífico", heroico; una magnificencia ritual; una admirable y sorprendente plasticidad litúrgica, de cántico en trance de ser liberado en donde la palabra dicta su propia lección, señala sus propias acciones al hombre y le presenta la constancia de su pasión y de su gozo sumergido en la memoria del tiempo, en sus recuerdos y en sus alucinaciones:

¡Hijas del Partenón por siempre jóvenes,

en su eterno minuto detenidas!

¡Felices, oh lejanas silenciosas,

divinas resignadas al instante,

para quienes la muerte era tan solo

rocío matinal, brisa dorada!

¡Sí! otrora la muerte sonreía.

En el sueño del aura temblorosa

el mármol sensitivo era agua inmóvil,

surtidor en suspenso enmudecido...

Indolente la limpia primavera

florecía en la luz de los trigales

y vestía de cielo las columnas,

la sosegada estatua, las abejas...

\section{(“Quinto Canto")}

El poeta recorre la existencia y da fe del acontecimiento del hombre como ser que genera espirales de vida a partir de sus horrores y de sus enigmas, cuando es capaz de descifrar su raíz y sus alas con la obstinada pasión y la avidez que proporciona la reminiscencia y la anamnesis. Es entonces cuando la visión heroica surge de la palabra formalizada, y en una suerte de involución del sobresalto y del subterráneo rescata la simple y hermosa verdad de vivir:

Porque antaño la muerte era de música; y a suave amanecer se parecía, a vuelo arrobador hacia el olvido, y canción que se apaga en lontananza, a dulce desangrarse sin lamento

o el amor que nos vence al entregarse. (idem)

\section{Devoción por la literatura francesa y España en el corazón}

Juan Ríos tuvo en mucha estima a los simbolistas franceses: a Rimbaud, Mallarmé, Baudelaire. No estuvo ausente Apollinaire, que crea la palabra "surrealisme"; y, desde luego, la tanatofilia de Los Cantos de Maldoror del Conde de Lautréamont cuando la angustia -a decir de César Miró- sube hasta la garganta del poeta como si tuviera una cita con Kierkegaard que considera lo demoníaco desde el ángulo estético-metafísico (Le concept de l'angoisse. Gallimard, París, 1935). Leamos un fragmento donde se observa una atmósfera nocturnal:

Es sublime, verdaderamente sublime, escuchar los acribillados trinos de la sangre, abrir los ojos en el vértigo dulcísimo y contemplar la ascensión de las iluminaciones.

La nuca del hombre parece menos delicada que la del ciervo,

pero es suave y embriagadora como los bordes blancos del lodo.

Los que saben mirarse en los espejos, los despiertos bajo el ala del cuervo,

los que, para encender la última aurora, atesoran extasiados las tinieblas,

aceptan siempre la invitación al asesinato.

("Invitación al asesinato")

Igual que Vallejo en su desesperada invocación final a los niños de España, Juan Ríos en plena agonía de la Madre Espańa, llama a la solidaridad, a la esperanza, para que al final de la batalla venza el amor y la justicia, como parece decirnos en el siguiente fragmento

Moriría la muerte si la innominada presencia taciturna,

el derramado resplandor de la tristeza, la pálida 
mirada de la ausencia,

la diseminada esperanza entre las dos orillas del recuerdo,

floreciesen de pronto, germinasen incalculables, respondiesen...

¡Ah! ¡Si la voz inmensa, sumergida, el llamamiento silencioso,

la perpetua rosa del ansia bajo el alcohol de las estrellas

descubrieran su signo solidario, su imagen distinta; si el ensimismado anhelo abriera sus estrechas prisiones frente al tiempo,

si la luz cantara, como el agua del sediento, en nuestros ojos,

retornaría la muerte a su olvidado origen, moriría invisible, trastornada,

y el fraternal verano brotaría perenne de sus símbolos marchitos!

(“Segundo Canto")

El hombre, aisladamente, está condenado a la vida, que es para Juan Ríos un tránsito angustioso; pero a la vez, el hombre, como entidad, va realizando aquello que se canta a través de la poesía. En toda su obra hay verdadera obsesión por llevar al hombre hacia el mito colectivo y, como consecuencia, al cántico: "La Tierra es una hoguera que consume los sueños./ Pero el ardor del hombre justifica la vida".

Producto de una intensa percepción de la vida, del constante ejercicio poético, Ríos llega a la hondura conceptual. En pocos versos el poeta condensa toda una visión madura de la existencia, como podemos apreciar en los siguientes fragmentos:

Pasan raudos los años. Ardientes se consumen.

Pero el alma atesora su aromada ceniza,

y a los ojos asoma su residuo de lágrimas.

(...)

Nace la mar donde la mar acaba.

$\mathrm{Su}$ inmenso latido solitario la dispersa;

mas la tierra la abraza y la retiene,

¡oh delirio atado al mundo, oh plenitud fatal, desamparada,

oh desesperación que huyendo de la muerte va a la muerte!

\section{(“Quinto Canto”)}

En la genealogía poética de Juan Ríos no puede omitirse a ese notable poeta del malditismo, Isidoro

4 Augusto Tamayo Vargas. Literatura Peruana Tomo III, Lima, 1992: 848
Ducasse o Conde de Lautréamont, que le da a una diabólica impostura acentos de confesión, como se aprecia en sus Cantos de Maldoror. En Juan Ríos se advierte esta presencia del asunto tremendista cuando conjuga con los suyos los círculos infernales de Dante, que es donde está completo el fabulador de los castigos monstruosos:

Cuando la hinchada lechuza encendió sus candiles sibilantes, penetré en el sexto círculo concéntrico. Y -añorando lo que nunca fue- al bordo del obscuro, inacabable

monstruo me detuve. Entonces advertí el demente fulgor

del cielo en las pupilas de la fiera, vi asomarse el ángel por

los ojos de la bestia taciturna. ¡Velloso río de la noche, ciega

risa del mar, inicuas aves de paso, tumefacta ciudad, gibosos arrabales, flamígeras miradas!... ¡ Oh mis lívidos

pensamientos suspendidos sobre la girante música del vértigo!

("Las Tinieblas"-IV-)

La más bella transposición literaria del "infierno" de Dante en las letras del Perú fue ofrecida por Juan Ríos en su poema "Infierno Recuperado", que al decir del maestro Estuardo Núñez es una "de las arquitecturas poemáticas más cabales de la literatura hispanoamericana". ${ }^{5}$

\section{Conclusiones}

Luego de pasar revista a las obras de Tauro del Pino, Tamayo Vargas y Juan Ríos, podemos concluir lo siguiente:

- En general, los mitos aparecen con mucha fuerza en estos tres escritores por la capacidad que tienen para revelar raíces o esencias, tanto nacionales como universales.

- Una época convulsionada por grandes conflictos sociales tuvo una respuesta analítica y reflexiva de los miembros de esta generación. Esto fue hasta cierto punto natural. Siguiendo los pasos de Estuardo Núñez en su Panorama actual de la poesía peruana, de 1938, tanto Tauro del Pino como Tamayo Vargas nos legaron profundos y eruditos trabajos sobre la

5 Juan Ríos. Primera Antología Poética, p. 253. 
historia de la literatura peruana. Hay que subrayar que buena parte de los escritores del 30-36 fueron destacados maestros universitarios. En la parte que le corresponde a Ríos, además de la reflexión introyectiva que supone su poesía, buceó también en el tema pictórico para escarbar la esencia de un arte universal.

- En la obra de estos tres escritores se formaliza un sentimiento lírico y épico, de vanguardia y clasicismo a la vez, así como una permanente confrontación entre el pesimismo y el optimismo, de donde aflora, siempre, un heroico renacimiento de la vida y la esperanza.
- Estos escritores tuvieron que salir al extranjero para encontrar en el propio drama universal las fuentes de la verdad y la justicia humanas; Juan Ríos luchó a favor de la República, en la Guerra Civil Española; Tamayo y Tauro, junto con Carlos Cueto Fernandini y José Mejía Baca, viajaron a Europa en 1938, llegando a París quince días después de la muerte de César Vallejo. Consternados, pero entendiendo que la frustración es también un acicate, pasaron luego a Italia y Alemania y se llenaron los ojos de arte y de cultura universal. Al regresar al Perú declararon que si bien la mirada debía estar preferentemente en América, no es posible desinteresarse de los panoramas que brinda Europa.

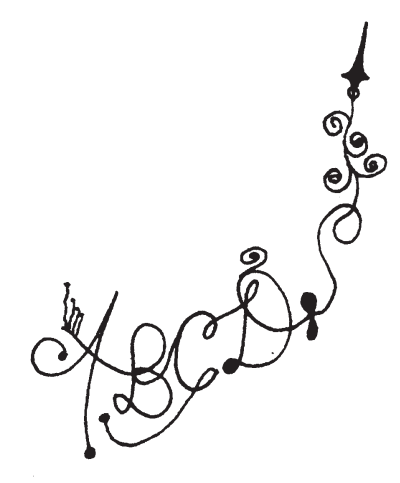

